Rev Biomed 2001; 12:290-291.

\title{
La sobrepoblación canina: un problema con repercusiones potenciales para la salud humana.
}

\section{Carta al Editor}

Antonio Ortega-Pacheco.

Departamento de Medicina Interna y Cirugía. Facultad de Medicina Veterinaria, Universidad Autónoma de Yucatán. Mérida, Yucatán, México.

Los perros son especies prolíficas que poseen características reproductivas muy particulares. Un trabajo realizado en la ciudad de Mérida, Yucatán, México muestra como estos tienen la capacidad de reproducirse todo el año, con ciertas tendencias hacia finales de primavera e inicio del verano (1). En 6 años una perra y sus crías, tienen la capacidad, a través de su descendencia, de producir 67,000 nuevos cachorros (2).

En Mérida, Yucatán cada año la perrera municipal sacrifica más de 2,000 perros. Muy pocos de ellos son reclamados y éstos son posteriormente eliminados por ser considerados como fauna nociva. Por otro lado, el número de perros atropellados y muertos en el anillo periférico y carreteras son incontables. Todo esto es originado por el problema de la sobrepoblación de esta especie, el cual no es provocado únicamente por el perro callejero sino que es un problema en el que todos nosotros estamos involucrados.

El problema de la sobrepoblación canina tiene un efecto directo en la salud humana ya que existen más de 65 enfermedades zoonóticas como la rabia, leptospirosis, anquilostomiasis, larva migrans, erliquiasis, brucelosis, cestodiasis, salmonelosis, entre otras, que los perros pueden transmitir (2). Esto tiene mayor impacto cuando los perros tienen acceso a la calle para defecar y orinar, puesto que los niños al jugar en jardines y parques públicos están a mayor riesgo de contagiarse con alguna de estas enfermedades.

Este problema se origina por el crecimiento incontrolado de la población canina el cual puede en 10 años crecer un $85 \%$ comparado con el $23.5 \%$ de crecimiento en la población humana (3). En ocasiones los perros son abandonados por sus

Solicitud de sobretiros: MVZ MVSc Antonio Ortega-Pacheco. Facultad de Medicina Veterinaria y Zootecnia, Universidad Autónoma de Yucatán, Km. 15.5 carretera Mérida-Xmatkuil, AP. 4-116, Mérida, Yucatán, México. 


\section{A Ortega-Pacheco.}

propietarios al darse cuenta de que no es lo que esperaban por razones tales como tener que alimentarlos, bañarlos y educarlos. Los problemas de comportamiento son una de las principales causas de abandono (4), los cuales son en su mayoría son fácilmente controlables. Estos perros, al tener acceso a la calle se reproducen libremente incrementando así la población de los mismos. Muchas veces la ignorancia de los propietarios agudiza más el problema puesto que "humanizamos" a nuestras mascotas y es de creencia popular tener que cruzarlos para evitar posibles traumas psicológicos. Es aquí donde los Médicos Veterinarios juegan un papel importante para educar a sus clientes sobre la reproducción de sus animales. Debe de evitarse en lo posible cruzar a sus animales y esterilizarlos lo más prontamente posible ya que esto además de disminuir la sobrepoblación de perros disminuye la probabilidad de que desarrollen tumores mamarios e infecciones uterinas. Existe una sobreoferta de perros, tanto de criadores profesionales como de criadores de "traspatio", siendo estos últimos aquellas personas con perros de cierta pureza racial que pensando en hacer negocio con su mascota la cruzan sin ningún control de calidad genética.

Este es un problema complejo que involucra a las autoridades de cada municipio para realizar estrategias efectivas que reduzcan el nacimiento de nuevos cachorros. No es suficiente una campaña de vacunación antirrábica si la población de esta especie no es controlada. Por otro lado las campañas de erradicación tampoco son efectivas. Esta última es una medida radical para un problema de educación y concientización de la población.

Palabras clave: Sobrepoblación canina, enfermedades zoonóticas.

\section{REFERENCIAS.}

1.- Ortega-Pacheco A, Rodríguez-Buenfil JC, Leal-Ortega J. Actividad estral de perros callejeros

\section{Revista Biomédica}

en la ciudad de Mérida y su relación con edad, tamaño y condición corporal. Rev Biomed 2000; 11:107-12.

2.- Faulkner L C. Dimensions of the pet population problem. JAVMA 1975; 166:477-8.

3.- Schneider R. Observations on overpopulation of dogs and cats. JAVMA 1975; 167:281-4.

4.- Patronek GJ, Beck AM, Glickman LT. Dynamics of dog and cat populations in a community. JAMVA 1997; 210:637-42. 